\title{
Talking about the Energy-saving Technical Measures in the Electrical Design of Buildings
}

\author{
School of Electrical and Information Engineering, Southwest Petroleum University, Chengdu, Sichuan 610500
}

\section{The characteristics of elec- trical design}

Now, as the people living for the improvement of quality of life, for the architectural design of lightning protection measures have gradually attached importance as well, so in the construction of electrical design process to mine the ground to do a good job to protect the owners for the safety of personal and property; in the process of electrical lighting design, have to take full view of the brightness of lighting and energy saving and environmental protection and other factors, such as: electrical lighting has been slowly began to use the delay control, automatic control and self-extinguishing lights and other intelligent control technology; power supply and distribution system design, the first thing to do is to rationally divide the high and low voltage cable, power supply radius to real-time control and have to sort out the rational distribution for reasonable wise. To ensure that the power supply and distribution system can be normal to run and its power supply are safety and high quality; according to the actual situation of the building to determine the electricity load and level, and then through scientific and rational calculation to ensure the accuracy of electricity load, scientific and rational on the selection of cables, power distribution equipment and power equipment, which to protect the economy of sustainable operation of equipment, in the most above the limit effectively avoid device power is not enough and so appear excessive and wasteful investment.
2 The current building electrical design of energy-saving technology analysis of the status quo

In the construction of the project, building electrical design is one of the most critical components, at present, people's increasing demand for electricity, most of the designers simply cannot guarantee the electrical design can be used to achieve the design of the norms and the standard, eventually leading to electrical installation errors. Electrical design and national standards corresponding to the discrepancy, in severe cases will occur blindly used on electricity phenomenon.

The main reason for the performance of the design because the designer is only blindly taking into account the user's demand for electricity, not in the construction of electrical design process will be fully aware of energy conservation awareness, so that not only increase the energy of the consumption, but also planted a security risk, in addition, most of our country will be the existence of energy shortages, not only businesses or individuals, in the lack of awareness of energy conservation, and ultimately the direct nature of the energy waste is very serious.

\section{Building electrical design of energy-saving technical mea- sures}

3.1 Energy-saving design and analysis of power supply and distribution system

The first thing to do is to carry

\begin{abstract}
At present, people pay more attention to the energy consumption of building electrical design, the use of energy-saving design can maximize the energy conservation resources, and ultimately increase the pace of social sustainable development. Therefore, the energy-saving designers involved in the need to follow the economic rational, safe and feasible benchmark to select the appropriate energy-saving measures to increase research and development of new technologies, new products and new energy, the concept of sustainable development to be implemented. In view of this, this paper mainly analyzes the energy saving technical measures in the electrical design of the building.
\end{abstract}

Key words: Building electrical; electrical design; energy saving technology

Published online: 15th July, 2017

out the actual verification of the total electricity consumption of the building, and the measured data as the basis of the voltage range in the distribution system, on the basis of the actual voltage to choose, usually the application of the voltage value is big. Followed by the maximum in order to achieve maximum energy 
savings, then and have to grasp the specific parts of the energy allocation, the load center for the optimal location. It can be seen that in the design process, to the power source as close as possible to the center of the load. Furthermore, it is necessary to apply the unit area power method, the binomial coefficient method and the coefficient method to the voltage, the total voltage of the statistical voltage. Finally, it controls the harmonics of the power distribution system and reduces the incidence of hazards due to electrical equipment.

3.2 Energy-saving design and analysis of transformers in electric power

In the process of building construction, the functions of the transformer are indispensable. For the overall electrical operation of the building has a direct control of the role and impact, and the transformer on the power application is also too large, in the process of loss is too much, so the transformer energy-saving design is very critical. According to the actual situation to analyze and transform the application of energy-saving method is preferred: the first choice of the transformer, you have to choose a reasonable capacity, so you can maximize the avoidance of waste phenomenon, but also can choose new low-energy transformer; the second is the internal structure of the transformer, to change their own way of running, the use of circuit or material to effectively change and increase the efficiency of the operation.

\subsection{Energy-saving design of electri- cal lighting}

First, for the full protection of the quality of lighting, we cannot blindly pursue energy saving regardless of their own lighting effects. Lighting system energy saving is to fully use the natural light way. Rely on a variety of ways to achieve the application of natural light in the building, and ultimately to the maximum to effectively reduce the energy consumption of artificial lighting. Second, in the lighting design, scientific and rational choice of light, the room for the requirements of the light source is different, the general room selection is fluorescent, then the general outdoor use of high pressure sodium lamp. Finally, the lighting system is used by the switch for energy-saving performance requirements are not the same, the application of energy-saving switch after the effect of its energy is very obvious.

In short, the key to ensuring the normal operation of the power system lies in the electrical design links, and the development of the construction industry is closely related. At present, the economic level of the rapid increase in people's demand is also otaku to increase, which gives the development of the construction industry opportunities also appeared in the energy shortage situation, we can see that this study is very meaningful.

\section{References:}

[1] Song Wei. On the Building Electrical Design of Energy-Saving Measures [J]. Technology and enterprises, 2016, (01): 101-102.

[2] Zhang Hao. Building Electrical Design in the Application of Energy-Saving Technology [A]. Xinjiang Uygur Autonomous Region Civil Building Society. Under the new normal green building development theory and practice - the fifth session of the central and western regions of China Civil Engineering Academic Conference Proceedings [C]. Xinjiang Uygur Autonomous Region Civil Building Society: 2015: 4.

[3] Li Yang. Construction of Electrical Design in the Application of Energy-Saving Technology $[A]$. Xinjiang Uygur Autonomous Region Civil Building Society. New normal under the green building development theory and practice - the fifth session of the Central and Western China Civil Engineering Academic Annual Meeting Proceedings of the Xinjiang Uygur Autonomous Region Civil Building Society: 2015: 4.

[4] Zheng Fengchao, Wu Jie. Talking about the Application of Energy Saving Technology in Building Electrical Design [J]. Doors and windows, 2014, (11): 243-247.

[5] Ren Hong Lu. In the Building
Electrical Design of Energy-Saving Technical Measures [J]. Heilongjiang Science and Technology Information, 2014, (22): 255.

[6] Li Jiangfan. Building Electrical Design of Energy-Saving Measures [A]. Hubei Provincial Civil Engineering Society of Architectural Electricity Committee, Wuhan City Civil Engineering Society of Architectural Electricity Committee, Hubei Province, electrical design and technical cooperation and information exchange network. Electrical Design and Research - Hubei Province / Wuhan City Construction Electrical Professional Committee 2009 Annual Conference Proceedings [C]. Hubei Provincial Civil Engineering Society Building Electrical Professional Committee, Wuhan City Civil Engineering Society Building Electrical Professional Committee, Hubei Province Architectural Electrical Design Technology Collaboration and Information Exchange Network: 